\title{
Article \\ Effect of Thermal Debinding Conditions on the Sintered Density of Low-Pressure Powder Injection Molded Iron Parts
}

\author{
Atefeh A. Tafti ${ }^{1, *(\mathbb{D},}$, Vincent Demers ${ }^{1}\left(\right.$, Seyed Mohammad Majdi ${ }^{1}$, Guillem Vachon ${ }^{2}$ and Vladimir Brailovski ${ }^{1}(\mathbb{D}$ \\ 1 Department of Mechanical Engineering, École de Technologie Supérieure, 1100 Notre-Dame West, \\ Montréal, QC H3C 1K3, Canada; vincent.demers@etsmtl.ca (V.D.); \\ seyed-mohammad.majdi.1@ens.etsmtl.ca (S.M.M.); vladimir.brailovski@etsmtl.ca (V.B.) \\ 2 Research and Development, Rio Tinto Metal Powders, 1625 Route Marie-Victorin, \\ Sorel-Tracy, QC J3R 4R4, Canada; guillem.vachon@riotinto.com \\ * Correspondence: atefeh.ayatollahi-tafti.1@ens.etsmtl.ca
}

check for updates

Citation: Tafti, A.A.; Demers, V.; Majdi, S.M.; Vachon, G.; Brailovski, V. Effect of Thermal Debinding Conditions on the Sintered Density of Low-Pressure Powder Injection Molded Iron Parts. Metals 2021, 11, 264. https://doi.org/10.3390/ met11020264

Academic Editor: Ilaria Cristofolini

Received: 8 January 2021

Accepted: 30 January 2021

Published: 4 February 2021

Publisher's Note: MDPI stays neutral with regard to jurisdictional claims in published maps and institutional affiliations.

Copyright: (c) 2021 by the authors. Licensee MDPI, Basel, Switzerland. This article is an open access article distributed under the terms and conditions of the Creative Commons Attribution (CC BY) license (https:/ / creativecommons.org/licenses/by/ $4.0 /)$.

\begin{abstract}
Low-pressure powder injection molding (LPIM) is a cost-effective technology for producing intricate small metal parts at high, medium, and low production volumes in applications which, to date, have involved ceramics or spherical metal powders. Since the use of irregular metal powders represents a promising way to reduce overall production costs, this study aims to investigate the potential of manufacturing powder injection molded parts from irregular commercial iron powders using the LPIM approach. To this end, a low viscosity feedstock was injected into a rectangular mold cavity, thermally wick-debound using three different pre-sintering temperatures, and finally sintered using an identical sintering cycle. During debinding, an increase in pre-sintering temperature from 600 to $850{ }^{\circ} \mathrm{C}$ decreased the number of fine particles. This decreased the sintered density from 6.2 to $5.1 \mathrm{~g} / \mathrm{cm}^{3}$, increased the average pore size from 9 to $14 \mu \mathrm{m}$, and decreased pore circularity from 67 to $59 \%$.
\end{abstract}

Keywords: low-pressure powder injection molding (LPIM); debinding; pre-sintering temperature; sintering; iron powder; irregular particles

\section{Introduction}

Powder injection molding (PIM) has been emerging as an alternative technology to conventional powder metallurgy thanks to its numerous strong points, such as high shape complexity and productivity, good precision, and adequate surface quality [1-3]. In ceramic injection molding (CIM) or metal injection molding (MIM), ceramic or metallic powders are mixed with a polymeric binder to form molten feedstocks that are injected into a mold cavity at a given injection pressure. During subsequent debinding and sintering processes, the binder is removed from the injected components, which are finally densified to obtain final products $[4,5]$. Although each processing stage is important, powder-binder formulation and binder removal are critical steps driving the PIM parts' final chemical composition and mechanical properties [6,7].

In conventional high-pressure powder injection molding (HPIM), the binder, which consists of a blend of low- and high-molecular-weight polymers (also called primary and secondary binders, respectively), is removed in two steps. During the first step, the primary binder is extracted either by a solvent [8-10], a supercritical fluid such as supercritical carbon dioxide [11,12], or a catalyst such as highly concentrated nitric acid $[13,14]$, depending on the binder system and powder characteristics. During the second step, the secondary binder, acting as a backbone to retain the shape, is removed during a final burnout cycle before the sintering process $[15,16]$. During the MIM process, several chemical reactions such as oxidation, reduction, carburization, and decarburization may occur during debinding and sintering, affecting the parts' magnetic, electric, physical, and mechanical properties. 
Since the carbon content determines the iron-based systems' properties, debinding and sintering processes need to be carefully designed to minimize undesirable chemical reactions. Ho et al. [17] investigated the decomposition behavior of a carbonyl iron powder (CIP) feedstock using one-step thermal and two-step solvent/thermal debinding routes. Using the same thermal debinding conditions (i.e., debinding at $500{ }^{\circ} \mathrm{C}$ under a hydrogen atmosphere), they confirmed that the carbon content was better controlled during a two-stage solvent/thermal debinding, as compared to the one-step thermal debinding route. Applying a similar two-step debinding approach to an iron-based feedstock, Hwang et al. [18] successfully extracted the primary soluble binder through a heptane bath, followed by a final burnout of the backbone polymer during thermal debinding under different $\mathrm{N}_{2}-\mathrm{H}_{2}$ atmospheres. They highlighted that an increase in the hydrogen proportion significantly affects the carbon content, directly impacting the final sintered densities. Lee et al. [19] studied the effect of debinding parameters, such as the temperature and heating rate, on the residual carbon content in different neodymium-iron-boron feedstock formulations. Using a one-step thermal debinding approach, they demonstrated that the use of slower heating rates $(<1 \mathrm{~K} / \mathrm{min})$ and higher debinding temperatures (from 270 to $500{ }^{\circ} \mathrm{C}$ ) was effective in maintaining a low carbon content, which affects the magnetic properties of sintered specimens.

In low-pressure powder injection molding (LPIM), a low viscosity multi-component binder provides high molding capability while generating suitable powder-binder interactions, feedstock stability, and low segregation occurrence. The binder system, which does not contain a high melting point backbone polymer, is generally composed of wax-based carriers, surfactants, and thickening agents providing a feedstock viscosity typically below $20 \mathrm{~Pa} \cdot \mathrm{s}$, which requires an injection pressure below $1 \mathrm{MPa}$ (i.e., 50 to 200 times lower than the pressure required in HPIM) [20]. This low injection pressure streamlines the production process by decreasing the size of injection machines and the overall tooling size (as compared to reciprocating screw press and massive molds used in conventional HPIM). This leads to a cost-effective fabrication of intricate parts, either in low- or high-production volumes [21,22]. However, in the absence of a backbone binder, one of the main challenges encountered in the LPIM process is shape retention and a lack of brown strength since all the binder components are removed in just a single step during a thermal wick debinding stage. For LPIM feedstock, the approach consists of embedding the injected parts into a wicking powder bed (e.g., graphite, alumina, or other inert powders) and to heat it to the pre-sintering temperature under a protective atmosphere. The powder bed acts as a wicking medium to withdraw the molten binder out of the heated part. As physical support, it maintains the weak debound structure up to the pre-sintering of powder particles. In thermal wick debinding, the most critical parameters include a wicking medium pore size, debinding temperature, heating rate, protective atmosphere, and pre-sintering temperature, which must be all set to ensure the proper binder extraction, while avoiding undesirable stresses, distortions, defects, or chemical reactions [23].

As a pioneer in this field, German [24] described the mechanisms governing thermal wick debinding and the binder's two distinct structures through the powder network. On the one hand, a significant amount of the molten state binder is extracted from the injected parts by capillary forces as a connected liquid (also called the funicular state) within the porous wicking bed. On the other hand, while binder regions become isolated, residual binder remains trapped within the part (also called the pendular state). During a heating ramp-up to pre-sintering temperature, the binder is completely decomposed regardless of location (i.e., inside the part, as pendular bonds, or outside the part within the wicking media). Based on this model, an evolution of binder content is expected at different times of the process (e.g., at different debinding short shots) where the center of the part becomes poorer in the binder, while the wicking bed becomes richer in the binder. Using an alumina-based LPIM feedstock, Gorjan et al. [25] experimentally confirmed this evolution in binder content and the formation of distinct rich and poor binder zones within the part using interrupted debinding cycles. Following the binder exudation occurring 
at the early debinding stage due to a sudden change in binder volume, they suggested that a molten binder could be mobile or immobile, depending on the part and wicking powder pore sizes. However, other experimental data obtained by some research groups showed few inconsistencies with this model. Somasundram et al. [26] studied the mechanisms of thermal wick debinding for a zirconia-based LPIM commercial feedstock using an experimental approach. They observed a homogenous distribution of the binder through the parts during the debinding stage. They concluded that the binder was extracted concurrently from bigger and smaller pores in the compact regardless of location within the part. Kim et al. [27] used a commercial silicon nitride based LPIM feedstock to study additives' effect on the capillary extraction forces during thermal wick debinding treatment. They observed that binder systems containing ethylene-vinyl acetate behaved differently from those containing polyethylene wax in capillary extraction, weight loss, and debinding rate. The study also concluded that the transition from the funicular to pendular states and the capillary structure are significantly affected by binder homogeneity regardless of binder location within the part. According to these approaches used to describe the debinding mechanisms, there are no universal analytical models that can be directly applied to all powder/binder systems to predict the physical phenomena occurring during thermal wick debinding.

As an alternative, thermogravimetric analysis (TGA) has been used extensively to assess binder constituents' effect and debinding atmosphere on the binder degradation behavior. Combined with other experimental techniques, the decomposition temperature ranges obtained with a TGA can be used directly to design thermal debinding cycles. HWANG and TSOU [28] studied the decomposition behavior and degradation rates of individual binder constituents for iron-based feedstock using the TGA to better understand the decomposition stages and design the thermal debinding process. Xianfeng et al. [29] investigated the thermal degradation behavior and evolution of gaseous species during a thermal debinding of zirconia-based feedstock. The TGA results confirmed that the chemical nature of the powder could change the kinetic of binder decomposition. Xie et al. [30] used TGA coupled with FTIR spectrometry (TG-FTIR analysis) to quantitatively study and design the thermal debinding cycle for HPIM zirconia-based feedstocks and evaluate the effect of binder composition, decomposition rate, degradation temperature range, and products on the quality of debound parts. W.-K. You et al. [31] used the TGA approach to design a thermal wick debinding cycle adapted to spherical iron-based feedstocks (i.e., to blends of micrometric and nanometric powders). A few years later, the same research group confirmed the debindability of such HPIM spherical iron-based feedstocks using the thermal wick debinding approach under hydrogen [32]. Although the last decades have seen the successful development of thermal wick debinding in HPIM using analytical or experimental models, thermal wick debinding of LPIM ceramic-based feedstocks has received very little attention. In contrast, metal-based feedstocks containing either spherical or irregular powders have been simply ignored. Likewise, to the best of the authors' knowledge, the effect of the pre-sintering temperature on the sintered properties of LPIM metallic parts has not been explored. This work aims to demonstrate the capability to debound an irregular iron-based LPIM feedstock using a thermal wick debinding process and investigate the effect of the pre-sintering temperature on the density and pore structure of sintered parts.

\section{Materials and Methods}

The iron powder was provided by Rio Tinto Metal Powders (Sorel-Tracy, QC, Canada). Following the water atomization process, the powder was high-energy milled, screened down using a 325 mesh $(-45 \mu \mathrm{m})$, and measured using a laser diffraction particle sizing analyzer (Coulter LS13 320 Beckman, Fullerton, CA, USA). The particle size distribution characterized by a $\mathrm{D}_{10}, \mathrm{D}_{50}$, and $\mathrm{D}_{90}$ of about $1.8,16.6$ and $44.1 \mu \mathrm{m}$ is reported in Figure $1 \mathrm{a}$. The irregular morphology of the powder-binder mixture's dry powder and homogeneity were observed using a Hitachi 3600 scanning electron microscope (SEM)( Hitachi, Tokyo, Japan), as illustrated in Figure 1b,c. The feedstock was prepared by blending 55 vol.\% of 
iron powder with a multi-component binder system containing $42 \mathrm{vol} . \%$ of paraffin wax (PW) used as the main carrier, 2 vol.\% of stearic acid (SA) promoting the surfactant effect, and $1 \mathrm{vol} . \%$ of ethylene-vinyl acetate (EVA) used as a thickening agent to avoid the segregation phenomenon. These binder constituents were selected due to their extensive use in LPIM [33,34]. The solid loading reached in this study represents a typical value for irregular powders used in LPIM that are mainly reported for ceramic-based feedstocks $[35,36]$.
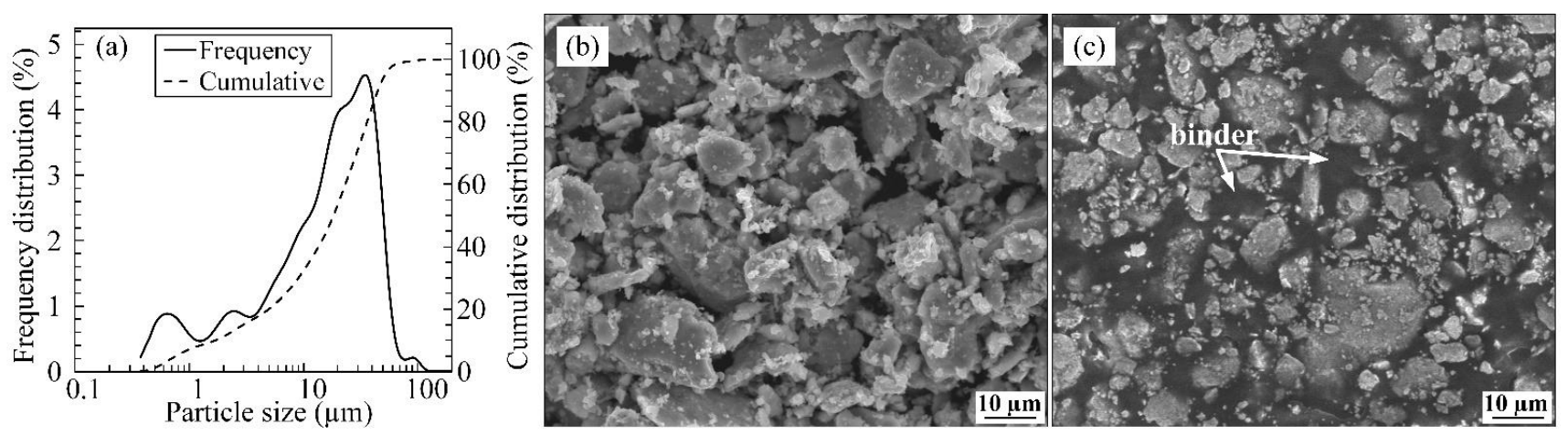

Figure 1. (a) Particle size distribution and SEM micrographs of (b) dry powder, and (c) feedstock.

The melting point of the feedstock was measured using a Perkin Elmer Pyris 1 differential scanning calorimeter (DSC) (Perkin Elmer, Waltham, MA, USA) according to ASTM D3418-03 [37], and the values for the second heating and cooling cycles are presented. During the test, a specimen of about $10 \mathrm{mg}$ was encapsulated in a standard aluminum pan and heated to temperatures ranging from 20 to $100^{\circ} \mathrm{C}$ using a heating rate of $10^{\circ} \mathrm{C} / \mathrm{min}$ under a protective atmosphere of dry nitrogen gas flow of $50 \mathrm{~mL} / \mathrm{min}$. Based on the DSC measurements, the rheological tests and injections' temperature was set to about $12{ }^{\circ} \mathrm{C}$ above the feedstock melting point to ensure its molten state. The feedstock viscosity was measured at $70{ }^{\circ} \mathrm{C}$ using a rotational rheometer (Anton Paar MCR 302, Graz, Austria) equipped with a concentric-cylinder geometry (CC-17) and a Peltier temperature-controlled measuring system (C-PTD 200, Anton Paar, Graz, Austria) at shear rates ranging from 0.5 to $1000 \mathrm{~s}^{-1}$. A thermogravimetric analysis (TGA) was performed using a simultaneous thermal analyzer (STA 8000, Perkin Elmer, Waltham, MA, USA) to obtain the feedstock's decomposition temperatures, which were later used to design the debinding cycles. To realize this test, a $10 \mathrm{mg}$ specimen was extracted from the injected part, placed in a standard platinum pan, and heated from 100 to $600{ }^{\circ} \mathrm{C}$ using a heating rate of $10{ }^{\circ} \mathrm{C} / \mathrm{min}$ under argon gas at a flow rate of $60 \mathrm{~mL} / \mathrm{min}$.

Injection molding was performed using the LPIM laboratory injection press specially designed to avoid the segregation that may occur when using a low viscosity feedstock [38]. During the injections into the rectangular mold illustrated in Figure 2a, a constant volumetric flow was maintained at $2.2 \mathrm{~cm}^{3} / \mathrm{s}$, producing a maximum injection pressure of about $0.5 \mathrm{MPa}$ for a mold temperature maintained at $45^{\circ} \mathrm{C}$. The injected parts were then embedded into an inert alpha-phase $99.9 \%$ alumina powder bed (Alfa Aesar, Thermo Fisher Scientific, stock \# 42572, Waltham, MA, USA) supported by a stainless-steel boat illustrated in Figure $2 b$. This boat was hermetically sealed within a metallic retort before the air was flushed with argon gas. The retort was placed in a programmable debinding furnace (Nabertherm L3117S, Lilienthal, Germany) and heated up to different pre-sintering temperatures under an inert atmosphere of argon, using a flow rate of $25 \mathrm{~L} / \mathrm{min}$. Three debinding cycles using two distinct stages (debinding and pre-sintering) were used to investigate the effect of pre-sintering temperature on the final sintered properties (debinding cycles are detailed in Section 3.2). A chemical analysis of the as-received powder and debound parts was performed by the infrared absorption method, using an oxygen analyzer (TC-500, LECO, St. Joseph, MI, USA) and a carbon analyzer (CS-200, LECO, St. Joseph, MI, USA). 
In contrast, the debound structures were observed using a scanning electron microscope (Hitachi 3600, secondary electron detector, Tokyo, Japan).

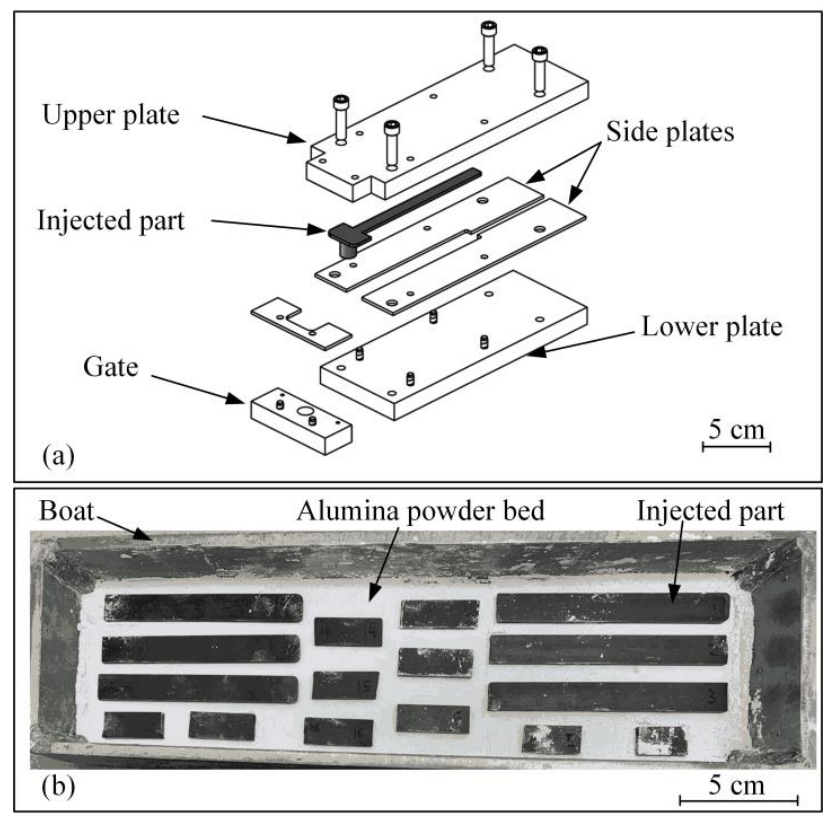

Figure 2. (a) Schematic representation of the rectangular mold and (b) typical arrangement of the injected parts settled on an alumina powder bed before debinding (top layer of alumina powder is not shown).

Debound specimens were settled on a dense zirconia plate and sintered in a hightemperature furnace (CM Furnace, model 1516 GSH2FL, Bloomfield, NJ, USA) using a typical sintering cycle for iron-based MIM parts [31]. It consisted of heating parts up to a sintering plateau at $1250{ }^{\circ} \mathrm{C}$ for $90 \mathrm{~min}$ under a reactive atmosphere of pure hydrogen (gas flow $\sim 30 \mathrm{~L} / \mathrm{min}$ ). The sintering temperature-time profile is shown in Figure 3. The sintered density was measured using the oil-impregnation method based on Archimedes' principle according to MPIF standard 42 [39]. Metallographic analyses were performed on cross-sections of the sintered specimens that were vacuum-impregnated with epoxy resin, cured at $60{ }^{\circ} \mathrm{C}$, mirror-polished, and observed using an optical microscope. A quantitative assessment of average pore size and circularity in sintered specimens was performed using the open-source image processing software ImageJ [40]. For the microstructure observation, the specimens were chemically etched in 2 vol.\% Nital solution $(2 \mathrm{~mL}$ of concentrated nitric acid in $98 \mathrm{~mL}$ of ethyl alcohol) and observed using an optical microscope.

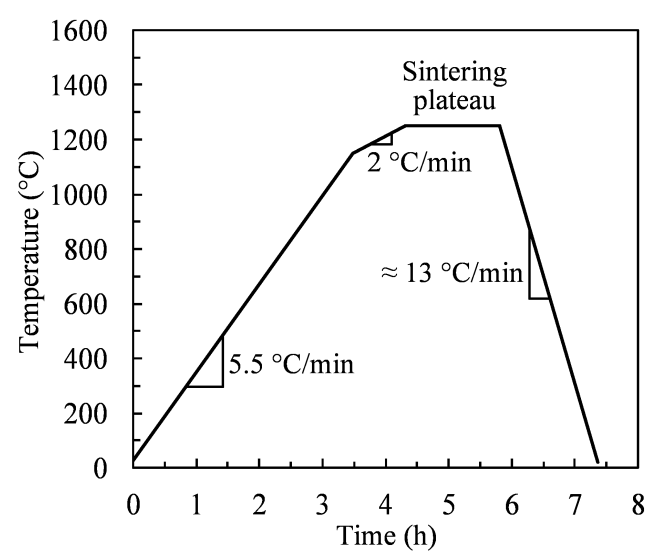

Figure 3. Sintering cycle under hydrogen atmosphere. 


\section{Results and Discussion}

\subsection{Feedstock Properties}

The DSC curve presented in Figure 4a manifests two distinct endothermic peaks corresponding to a multi-constituent binder's melting point. The feedstock melting point of $57.7^{\circ} \mathrm{C}$ was determined using the curve's last peak as indicated by the black arrow in Figure $4 \mathrm{a}$. The feedstock rheological profile measured at $70^{\circ} \mathrm{C}$ (Figure $4 \mathrm{~b}$ ) demonstrated that at this temperature, a range of typical shear strain rates experienced by a powder-binder mixture during the injection (10-100 s ${ }^{-1}$ ) corresponds to a feedstock viscosity ranging from 1.5 to $3 \mathrm{~Pa} \cdot \mathrm{s}$, which is below $20 \mathrm{~Pa} \cdot \mathrm{s}$ as recommended for the LPIM processing [20]. This temperature was selected as the feedstock temperature for injections.
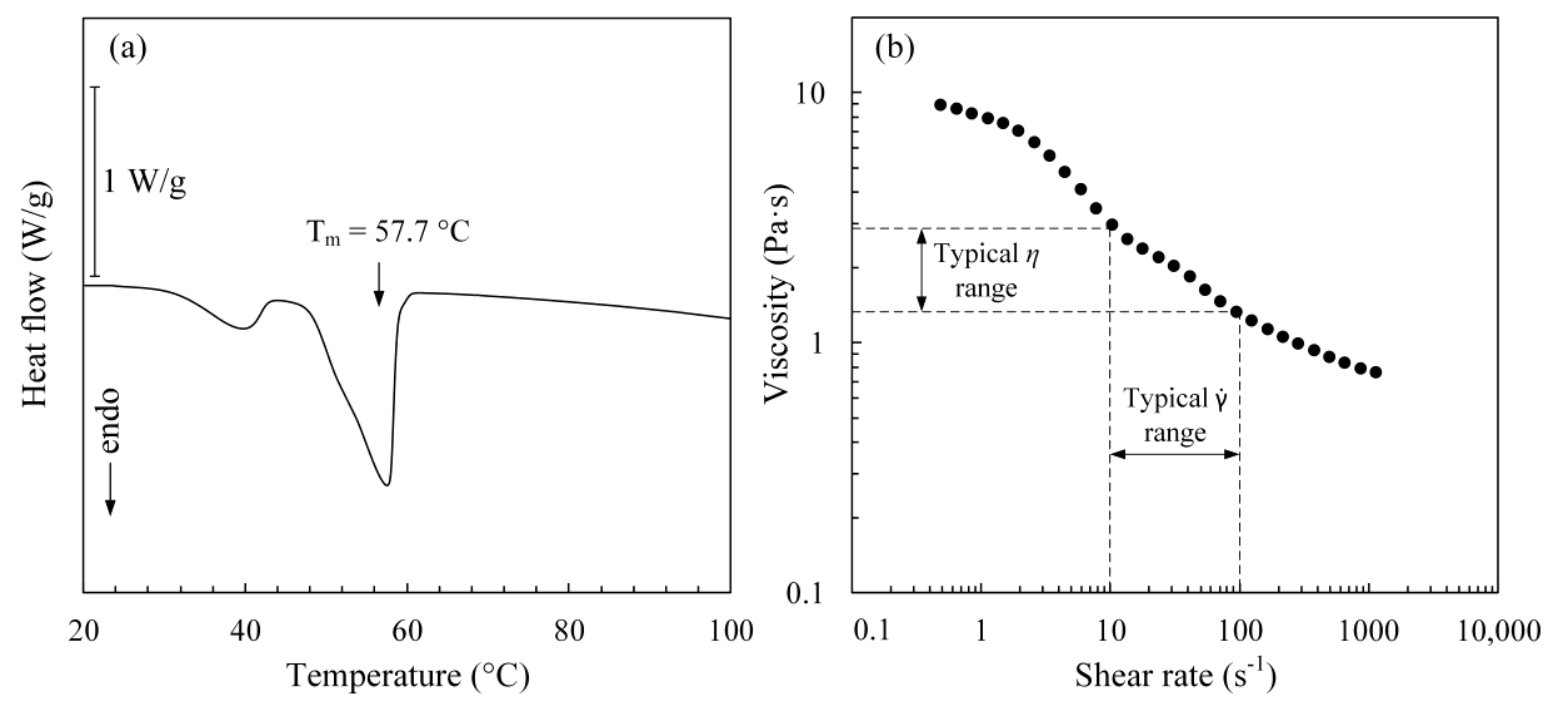

Figure 4. (a) Differential scanning calorimeter (DSC) profile and (b) viscosity profile of feedstock at $70{ }^{\circ} \mathrm{C}$.

\subsection{Debinding}

\subsubsection{Selection of Debinding and Pre-Sintering Temperatures}

Figure 5a presents the TGA profiles obtained for each binder constituent and the feedstock. The decomposition of individual binders SA, PW, and EVA starts at 150, 160, and $280{ }^{\circ} \mathrm{C}$, and ends at 380,470 , and $480^{\circ} \mathrm{C}$, respectively. The EVA decomposition curve exhibits two steps (the first ranging from $280-370{ }^{\circ} \mathrm{C}$ and the second, from $400-480{ }^{\circ} \mathrm{C}$ ) corresponding to acetic acid's thermal degradation polyethylene-co-acetylene, respectively [41]. The TGA curves confirm that these three binder constituents are completely decomposed at $480^{\circ} \mathrm{C}$. Although the binder is formulated from three constituents, the feedstock's TGA profile exhibits one single but broad decomposition step. The EVA and SA solubility can explain this change in the thermal decomposition kinetics between single and multiple binders in PW, which has been reported in previous work [42]. The change in weight fraction corresponds to the initial $\left(\mathrm{T}_{\mathrm{D} 1}\right)$ and final $\left(\mathrm{T}_{\mathrm{D} 2}\right)$ temperatures of binder burnout at 250 and $380^{\circ} \mathrm{C}$, respectively. The TGA profile obtained for the feedstock shows a remaining weight fraction of around $90 \mathrm{wt} . \%$, corresponding to the powder's relative weight initially contained in the mixture (i.e., a solid loading equivalent of $55 \mathrm{vol} \%$ ). 

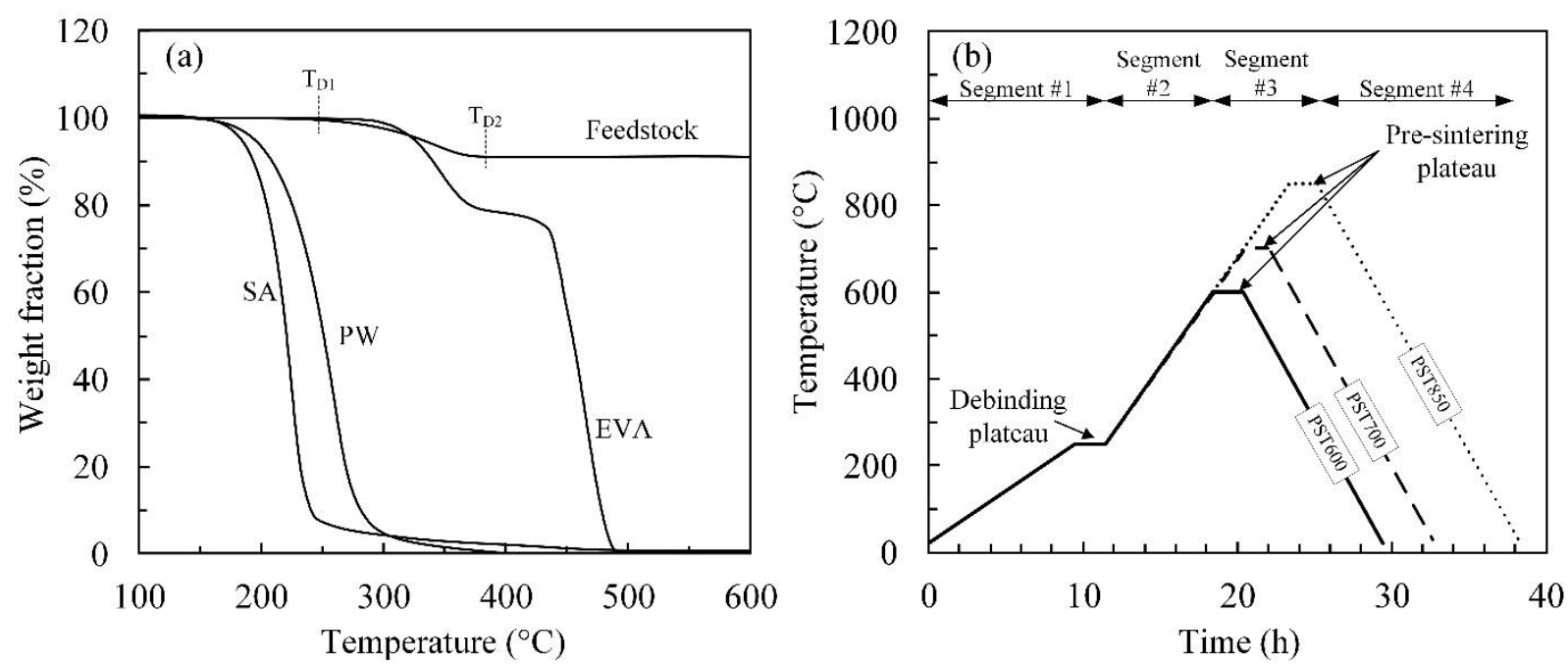

Figure 5. (a) TGA profiles of binder constituents (SA: stearic acid; PW: paraffin wax; EVA: ethylene vinyl acetate) and feedstock, and (b) thermal wick debinding cycles performed at different pre-sintering temperatures varying from 600 to $850{ }^{\circ} \mathrm{C}$ under argon atmosphere.

The values obtained from the TGA and DSC profiles were used to define the debinding and pre-sintering temperatures shown in Figure $5 \mathrm{~b}$. This heat treatment was designed to extract the binder from the injected parts and increase the brown strength (i.e., initiate particle bonding) required for handling and transfer the samples to the sintering treatment. The temperature for the debinding plateau (i.e., the binder removal phase reported as segment \#1 in Figure $5 b$ ) was set at $250{ }^{\circ} \mathrm{C}$, i.e., between $\mathrm{T}_{\mathrm{m}}$ and $\mathrm{T}_{\mathrm{D} 1}$, to guarantee the molten state of the binder while avoiding its thermal decomposition. During segment $\# 2$, the liquid binder, which was mainly absorbed by the wicking media, was burned out during the temperature ramp-up (over 6 to $12 \mathrm{~h}$, according to the pre-sintering temperature) starting above $\mathrm{T}_{\mathrm{D} 1}$ and exceeding $\mathrm{T}_{\mathrm{D} 2}$. In this work, three pre-sintering temperatures with a dwelling time of two hours at 600,700 , and $850^{\circ} \mathrm{C}$ were used to study the impact of this process parameter on the final sintered density, pore size, and structure (reported as segment \#3 in Figure 5b). Preliminary debinding tests confirmed that a pre-sintering temperature below $600{ }^{\circ} \mathrm{C}$ produced a bonding too weak to be handled, i.e., the brown parts were still in a near-loose powder state. In another exploratory trial, a pre-sintering temperature above $850{ }^{\circ} \mathrm{C}$ induced well-developed neck bonding similar to a fully sintered structure but did exhibit distortions probably due to the constrained state inherent to samples embedment into the alumina powder bed. Following the pre-sintering plateau, the specimens were slowly cooled down at approximately $1.6^{\circ} \mathrm{C} / \mathrm{min}$ maintaining an argon protective atmosphere until room temperature was reached (segment \#4 in Figure 5b). The heating and cooling rates were kept low to create a gradual binder wicking and minimize the temperature gradients through the green parts, which could cause distortions, cracking, blistering, or other undesirable defects [43]. Note that the impact of the cooling-heating rates on the quality of parts should be studied further to decrease the total cycle time.

\subsubsection{Debound Part Characterization}

The as-received powder and debound parts' carbon and oxygen contents are compared in Figure 6 for different pre-sintering temperatures. As expected, the as-received powder's initial carbon and oxygen levels are high due to an intrinsic affinity of wateratomized iron powders to oxygen, which forms stable iron oxides on particle surfaces [44]. After the debinding process, carbon decreased by a factor of 2, while the amount of oxygen decreased by approximately 10 times. Furthermore, a slight decrease in brown parts' carbon and oxygen contents was also seen as the pre-sintering temperature increased. The significant decrease in oxygen content can be explained by this element reaction on the powder's surface, with the carbon alloyed inside and the binder found between the 
particles. These results show that to design a proper debinding treatment for the MIM iron parts, optimizing the pre-sintering temperature is critical since shrinkage, structure, and mechanical properties are strongly affected by carbon content [45].

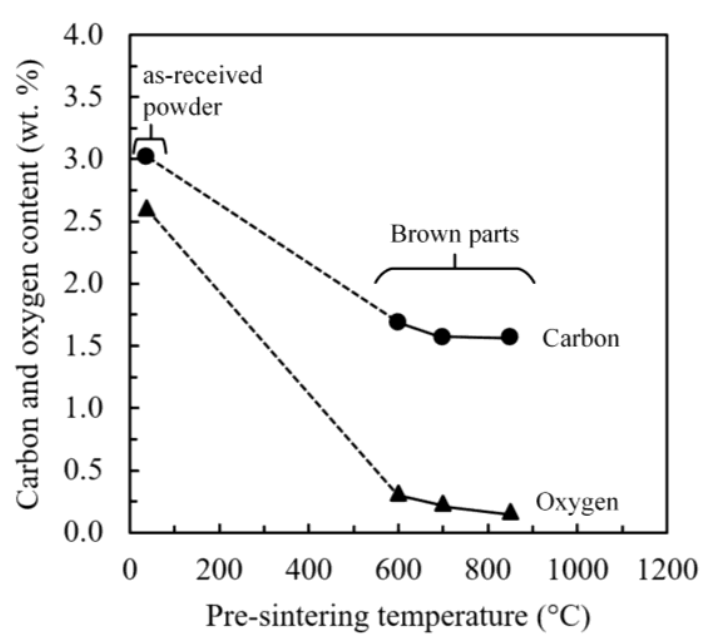

Figure 6. Evolution of the carbon and oxygen contents as functions of the pre-sintering temperature.

Debound specimens pre-sintered at different temperatures were broken to evaluate the bonding networks, as shown in Figure 7. After debinding, the center of all the debound parts exhibits many open channels regardless of the pre-sintering temperature used during the debinding cycle (Figure $7 \mathrm{a}-\mathrm{c}$ ). An increase in the pre-sintering temperature from 600 to $850^{\circ} \mathrm{C}$ appears to decrease fine loose powders, which seems to bond on coarse particles. Since these fine particles play an important role in the activation of sintering, using high pre-sintering temperatures may negatively affect the sintering driving force, and therefore, the final part density. Interestingly, large particles in the center of the debound network do not exhibit clear and well-defined neck bonding but rather, a network similar to loose powder particles interlocked together.

Looking at the edge of the debound specimens, the SEM observations shown in Figure $7 \mathrm{~d}-\mathrm{f}$ confirm the presence of three distinct zones. Zone \#1 is similar to the one observed in the specimens' center, where no apparent bonding is found. Zone \#2 is a sub-surface region where some bonding can be observed under all debinding conditions. Although these two zones are visible regardless of the pre-sintering temperature, a third zone exhibiting a dense layer can be observed in Figure 7e,f was only acknowledged in the specimens debound at high temperatures (i.e., pre-sintered at 700 and $850^{\circ} \mathrm{C}$ ). An explanation for this phenomenon is that an increase in the pre-sintering temperature provides the thermal activation energy sufficient to sinter the parts' surface. However, some research groups have reported a similar surface phenomenon during the thermal wick debinding of different ceramic-based feedstocks formulated from paraffin wax binders [46,47]. Zorzi et al. [48] and Gorjan et al. [49] proposed another explanation, in which this nonvolatile layer was formed during a thermal debinding above $250{ }^{\circ} \mathrm{C}$ due to an intricate chemical reaction taking place between paraffin wax and alumina powder at the interface of the part and the wicking medium, transforming the hydrocarbon binder into a dense layer. Considering the use of an inert protective atmosphere in our work, this second hypothesis explaining this dense layer formation could be linked to the quantity of oxygen and impurities adsorbed. They are usually in the form of an oxide layer on the particles' surface, which could intensify such an insoluble layer. Although this phenomenon's study is beyond the scope of this work, it is interesting to note that the thickness of this dense layer seems to increase with the pre-sintering temperature. Therefore, the strength observed after debinding at different pre-sintering temperatures for this irregular powder seems to be explained by the powder interlocking combined with the occurrence of solid-state bonds when present on the specimen surface. 

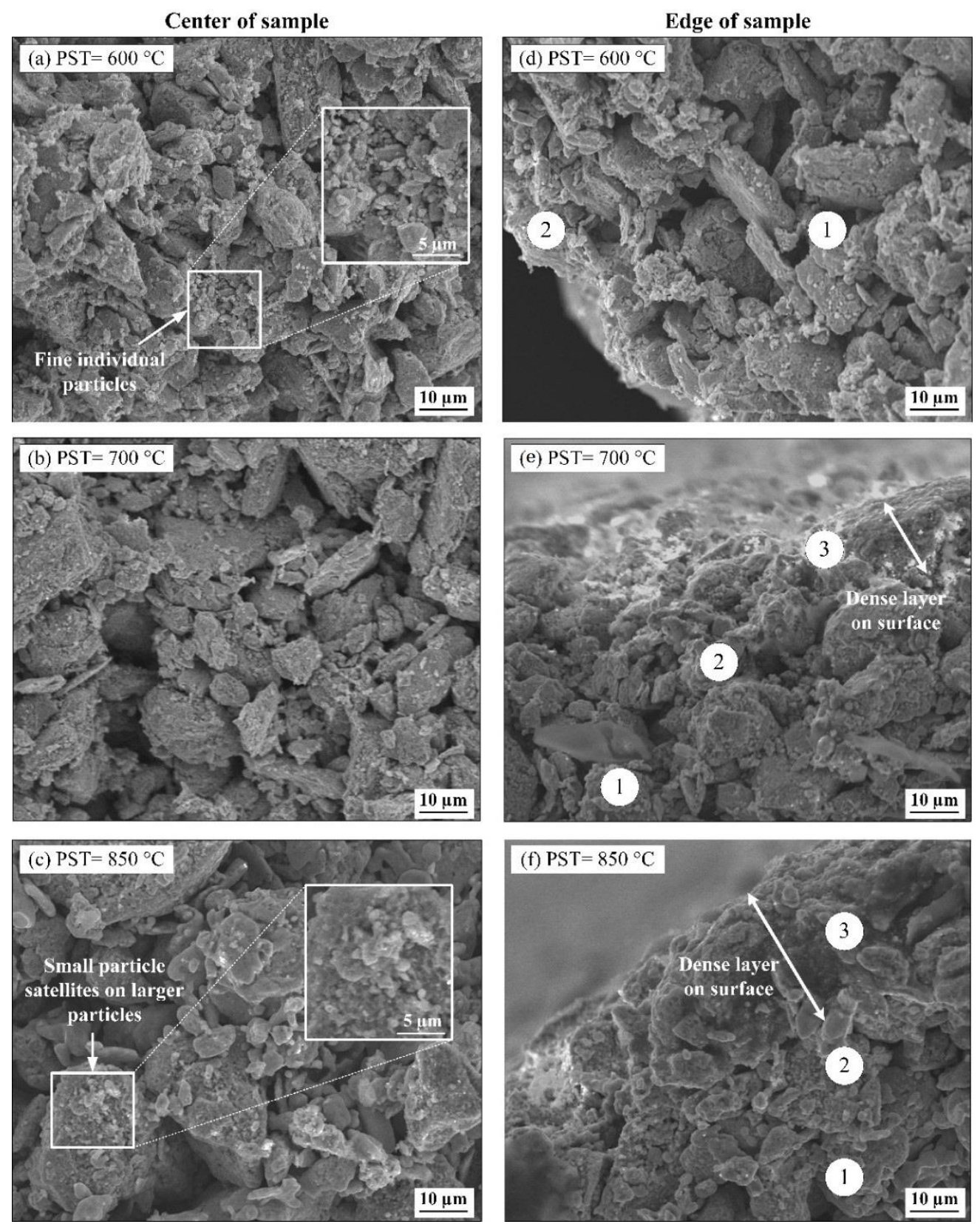

Figure 7. SEM observations of the debound specimens $(\mathbf{a}-\mathbf{c})$ at the center and $(\mathbf{d}-\mathbf{f})$ at the specimens' edge.

\subsection{Sintered Properties}

As observed in Figure 8a, the debinding stage produces no significant shrinkage as compared to the injected part, since debinding treatment produced no real bonding. After sintering, a linear shrinkage of about $12 \%$ was measured. The sintered density of the specimens debound at different pre-sintering temperatures is presented in Figure $8 b$. Globally, the highest final sintered density, about $80 \%$ of the theoretical value, was achieved for the parts debound-pre-sintered at $600{ }^{\circ} \mathrm{C}$. As the pre-sintering temperature increases from 600 to $850{ }^{\circ} \mathrm{C}$, the sintered density decreases from 6.2 to $5.1 \mathrm{~g} / \mathrm{cm}^{3}$, which is in line with the metallographic analysis presented in Figure 9, where the occurrence and size of interconnected pores increase as the pre-sintering temperature increases. The smallest volume fraction of pores was obtained with the specimen debound at $600{ }^{\circ} \mathrm{C}$, and to a smaller extent, at $700{ }^{\circ} \mathrm{C}$. The well-distributed isolated pores seen in Figure $9 \mathrm{a}, \mathrm{b}$ confirm that these low pre-sintering temperatures resulted in a better sinterability that could be explained by the presence of fine particles observed within the debound network 
of Figure $7 a, b$, combined with the mitigation of undesirable chemical reactions such as contamination, interstitial elements, or surface oxidation.

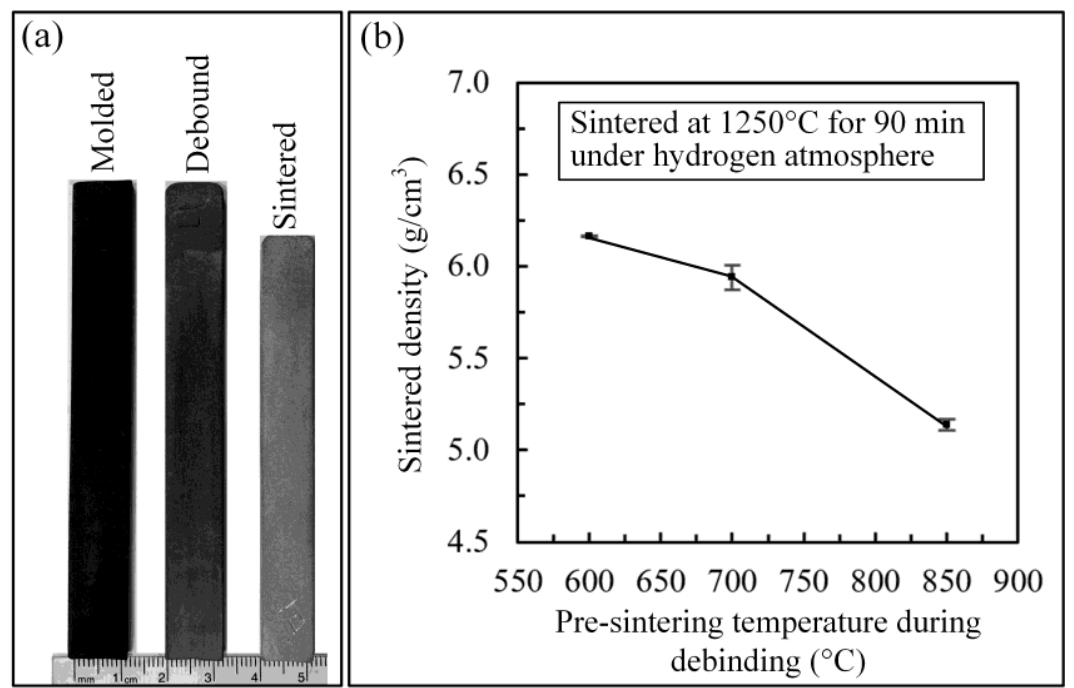

Figure 8. (a) Dimensional comparison of injected, debound-pre-sintered at $600{ }^{\circ} \mathrm{C}$, and sintered specimens, (b) sintered densities of specimens debound using different pre-sintering temperatures.

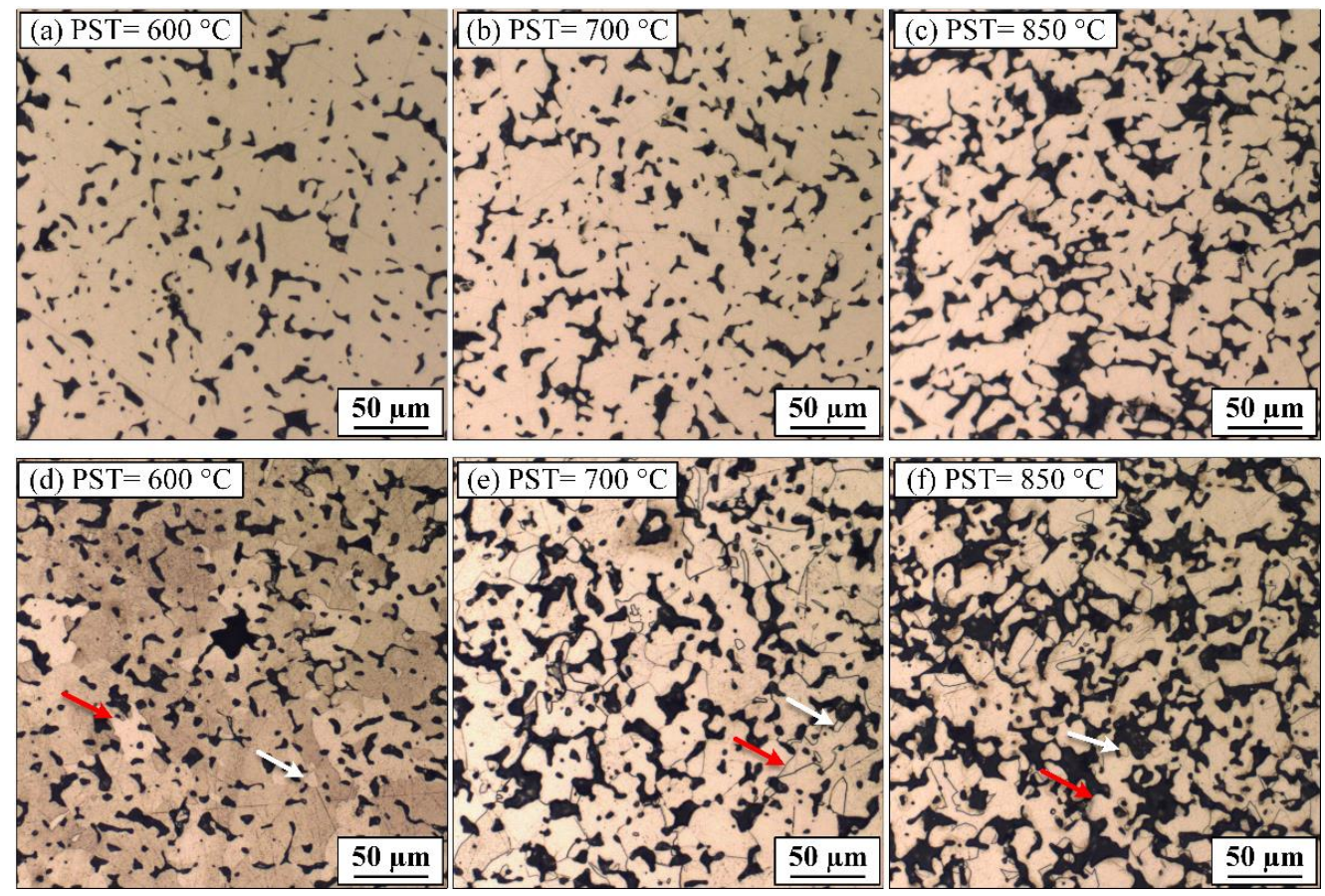

Figure 9. Optical micrographs of $(\mathbf{a}-\mathbf{c})$ as-polished, $(\mathbf{d}-\mathbf{f})$ etched specimens sintered at $1250{ }^{\circ} \mathrm{C}$ under hydrogen atmosphere following different pre-sintering temperatures.

On the other hand, the optical micrograph of the specimen debound at $850{ }^{\circ} \mathrm{C}$ (Figure 9c) exhibits the highest degree of interconnected pores along with several interparticle joints. From the metallographic images of sintered microstructures presented in Figure $9 \mathrm{~d}-\mathrm{f}$, it was observed that regardless of the debinding-pre-sintering temperature (PST), these microstructures manifest a bimodal grain size distribution consisting of small grains with an average size of $\sim 6 \mu \mathrm{m}$. White arrows indicate it in Figure $9 \mathrm{~d}-\mathrm{f}$, and large grains with an average size of $\sim 30 \mu \mathrm{m}$, indicated by red arrows in Figure $9 \mathrm{~d}-\mathrm{f}$. However, for PST of $700{ }^{\circ} \mathrm{C}$ and $850{ }^{\circ} \mathrm{C}$, small grains appear to be located mostly at the pore interfaces on the densified clusters' periphery. In contrast, for PST of $600{ }^{\circ} \mathrm{C}$, small grains are 
well-distributed throughout the densified material. The specific small grain distributions observed after high-temperature PST could be due to satellites sintered on large particles after the debinding process that was apparently not contributing to the sintering driving force required for further densifying the part.

Figure 10 illustrates the evolution of average pore size and circularity as functions of the pre-sintering temperature. It could be observed that the higher the pre-sintering temperature, the larger the pore size (an increase in the average size from 9 to $14 \mu \mathrm{m}$ ) and the lower the pore circularity (a decrease in average circularity from 67 to 59\%). Such increased pore size and decrease in pore circularity produce a reduction in the MIM parts' mechanical properties. Moreover, since fine particles observed during debindingpre-sintering at $600{ }^{\circ} \mathrm{C}$ can be considered as the major sintering driving force (presented in Figure $7 \mathrm{a}, \mathrm{b})$, it can be concluded that the pre-sintering temperature must be kept as low as possible to prevent their annihilation while minimizing undesirable chemical reactions during debinding. In this respect, the sintering process (heating ramp, oxide reduction temperature, sintering temperature, dwell time, etc.) must be optimized to confirm whether the final density can be improved.

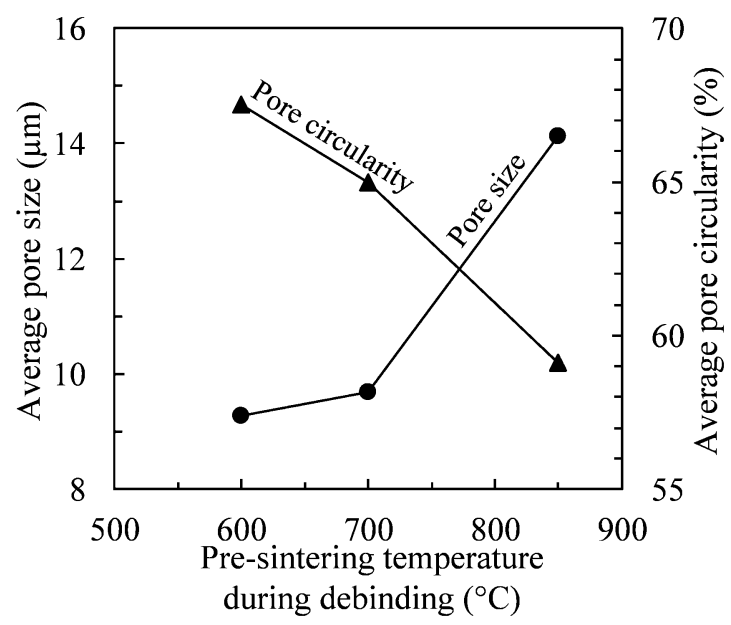

Figure 10. Average pore size and circularity as functions of pre-sintering temperature.

\section{Conclusions}

A low-pressure powder injection molding (LPIM) approach was used to inject an irregular iron-based feedstock, which was finally debound and sintered. A low viscosity feedstock was formulated from one irregular iron-based powder $(\mathrm{D} 50=16.6 \mu \mathrm{m})$ and one wax-based binder system (paraffin wax, stearic acid, and ethylene-vinyl acetate) at a solid loading of $55 \mathrm{vol} . \%$ and injected into a rectangular mold cavity. The green parts were thermally wick-debound using three different pre-sintering temperatures $(600,700$, and $850^{\circ} \mathrm{C}$ ), and finally sintered using the same profile at $1250^{\circ} \mathrm{C}$ under a hydrogen atmosphere for $90 \mathrm{~min}$. The conclusions are summarized as follows:

- The low viscosity $\left(<3 \mathrm{~Pa} \cdot \mathrm{s}\right.$ at $\left.10 \mathrm{~s}^{-1}\right)$ and low melting point $\left(\sim 58^{\circ} \mathrm{C}\right)$ confirm that a powder-binder mixture formulated from irregular iron powder at a solid loading of $55 \mathrm{vol} . \%$ is suitable for the LPIM process.

- The debinding process decreased the amount of oxygen by 10 times and the amount of carbon by factor 2 compared to the as-received powder. Furthermore, a slight decrease in carbon and oxygen content was observed as the pre-sintering temperature increased.

- An increase in pre-sintering temperature from 600 to $850{ }^{\circ} \mathrm{C}$ decreases the occurrence of fine loose powder distributed within the debound network. It promotes bonding at the surface (dense layer) and the sub-surface (particles bonding) regions. The decrease in sintered density from 6.2 to $5.1 \mathrm{~g} / \mathrm{cm}^{3}$, along with a higher degree of interconnected pores observed with an increase in the pre-sintering temperature, confirms that this debinding parameter is important and must be kept as low as possible during thermal 
wick debinding. In this respect, thermal wick debinding using a low pre-sintering temperature produced no clear bonding on this irregular iron powder (i.e., a network similar to loose powder interlocked together), leading to no significant shrinkage, as compared to the as-injected part.

- To the best of the authors' knowledge, this study represents for the first time the capability to debound metallic-based LPIM feedstock using a thermal wick debinding approach that has been presented.

Author Contributions: A.A.T. carried out the experiments, analyzed the results, and wrote the manuscript; V.D. supervised the experiments and edited the manuscript, S.M.M. carried out the experiments, G.V. edited the manuscript, V.B. managed the project and edited the manuscript. All authors have read and agreed to the published version of the manuscript.

Funding: This work was carried out with the Natural Sciences and Engineering Research Council of Canada's financial support, grant number CRDPJ505289-16.

Data Availability Statement: Data sharing not applicable.

Acknowledgments: The financial support of the Natural Sciences and Engineering Research Council of Canada (NSERC) is gratefully acknowledged.

Conflicts of Interest: The authors declare no conflict of interest.

\section{References}

1. German, R.M.; Bose, A. Injection Molding of Metals and Ceramics; Metal Powder Industries Federation: Princeton, NJ, USA, 1997.

2. German, R.M. Progress in titanium metal powder injection molding. Materials 2013, 6, 3641-3662. [CrossRef]

3. Hamidi, M.F.F.A.; Harun, W.S.W.; Samykano, M.; Ghani, S.A.C.; Ghazalli, Z.; Ahmad, F.; Sulong, A.B. A review of biocompatible metal injection moulding process parameters for biomedical applications. Mater. Sci. Eng. C 2017, 78, 1263-1276. [CrossRef]

4. Checot-Moinard, D.; Rigollet, C.; Lourdin, P. Powder injection moulding PIM of feedstock based on hydrosoluble binder and submicronic powder to manufacture parts having micro-details. Powder Technol. 2011, 208, 472-479. [CrossRef]

5. Rueda, M.M.; Auscher, M.C.; Fulchiron, R.; Périé, T.; Martin, G.; Sonntag, P.; Cassagnau, P. Rheology and applications of highly filled polymers: A review of current understanding. Prog. Polym. Sci. 2017, 66, 22-53. [CrossRef]

6. Kang, T.G.; Ahn, S.; Chung, S.H.; Chung, S.T.; Kwon, Y.S.; Park, S.J.; German, R.M. Modeling and simulation of metal injection molding (MIM). In Handbook of Metal Injection Molding; Woodhead Publishing: Cambridge, UK, 2012; pp. $219-252$.

7. Enneti, R.K.; Onbattuvelli, V.P.; Gulsoy, O.; Kate, K.H.; Atre, S.V. Powder-Binder Formulation and Compound Manufacture in Metal Injection Molding (MIM). In Handbook of Metal Injection Molding, 2nd ed.; Heaney, D.F.B.T.-H., Ed.; Woodhead Publishing Series in Metals and Surface Engineering; Woodhead Publishing: Cambridge, UK, 2019; pp. 57-88. [CrossRef]

8. Hayat, M.D.; Wen, G.; Zulkifli, M.F.; Cao, P. Effect of PEG molecular weight on rheological properties of Ti-MIM feedstocks and water debinding behavior. Powder Technol. 2015, 270, 296-301. [CrossRef]

9. Hayat, M.D.; Goswami, A.; Matthews, S.; Li, T.; Yuan, X.; Cao, P. Modification of PEG/PMMA binder by PVP for titanium metal injection moulding. Powder Technol. 2017, 315, 243-249. [CrossRef]

10. Rane, K.K.; Date, P.P. A dimensional analysis based model to predict completion of solvent debinding step for Metal Injection Moulded parts. Adv. Mater. Process. Technol. 2020. [CrossRef]

11. Chartier, T.; Ferrato, M.; Baumard, J.F. Supercritical debinding of injection molded ceramics. J. Am. Ceram. Soc. 1995, 78, 1787-1792. [CrossRef]

12. Royer, A.; Barriere, T.; Bienvenu, Y. Influence of supercritical debinding and processing parameters on final properties of injection-moulded Inconel 718. Powder Technol. 2018, 336, 311-317. [CrossRef]

13. Krug, S.; Evans, J.R.G.; Maat, J.H. Reaction and transport kinetics for depolymerization within a porous body. AIChE J. 2002, 48, 1533-1541. [CrossRef]

14. Attia, U.M.; Hauata, M.; Walton, I.; Annicchiarico, D.; Alcock, J.R. Creating movable interfaces by micro-powder injection moulding. J. Mater. Process. Technol. 2014, 214, 295-303. [CrossRef]

15. Hayat, M.D.; Jadhav, P.P.; Zhang, H.; Ray, S.; Cao, P. Improving titanium injection moulding feedstock based on PEG/PPC based binder system. Powder Technol. 2018, 330, 304-309. [CrossRef]

16. Park, J.M.; Han, J.S.; Gal, C.W.; Oh, J.W.; Kate, K.H.; Atre, S.V.; Kim, Y.; Park, S.J. Effect of binder composition on rheological behavior of PMN-PZT ceramic feedstock. Powder Technol. 2018, 330, 19-26. [CrossRef]

17. Ho, Y.L.; Lin, S.T. Debinding variables affecting the residual carbon content of injection-molded Fe-2 Pct Ni steels. Metall. Mater. Trans. A 1995, 26, 133-142. [CrossRef]

18. Hwang, K.S.; Hsieh, C.H.; Shu, G.J. Comparison of mechanical properties of Fe-1.75Ni-0.5Mo-1.5Cu-0.4C steels made from PIM and press and sinter processes. Powder Metall. 2002, 45, 160-166. [CrossRef] 
19. Lee, S.H.; Choi, J.W.; Jeung, W.Y.; Moon, T.J. Effects of binder and thermal debinding parameters on residual carbon in injection moulding of $\mathrm{Nd}(\mathrm{Fe}, \mathrm{Co}) \mathrm{B}$ powder. Powder Metall. 1999, 42, 41-44. [CrossRef]

20. Sardarian, M.; Mirzaee, O.; Habibolahzadeh, A. Influence of injection temperature and pressure on the properties of alumina parts fabricated by low pressure injection molding (LPIM). Ceram. Int. 2017, 43, 4785-4793. [CrossRef]

21. Sajko, M.; Kosmač, T.; Dirscherl, R.; Janssen, R. Microstructure and mechanical properties of low-pressure injection-moulded reaction-bonded alumina ceramics. J. Mater. Sci. 1997, 32, 2647-2654. [CrossRef]

22. Mangels, J.A. Low-pressure injection molding. Am. Ceram. Soc. Bull. 1994, 73, 5.

23. Patterson, B.R.; Aria, C.S. Debinding injection molded materials by melt wicking. JOM 1989, 41, 22-25. [CrossRef]

24. German, R.M. Theory of thermal debinding. Int. J. Powder Metall. 1987, 23, 237-245.

25. Gorjan, L.; Dakskobler, A.; Kosmač, T. Partial wick-debinding of low-pressure powder injection-moulded ceramic parts. J. Eur. Ceram. Soc. 2010, 30, 3013-3021. [CrossRef]

26. Somasundram, I.M.; Cendrowicz, A.; Wilson, D.I.; Johns, M.L. Phenomenological study and modelling of wick debinding. Chem. Eng. Sci. 2008, 63, 3802-3809. [CrossRef]

27. Kim, S.W.; Lee, H.W.; Song, H.; Kim, B.H. Pore structure evolution during solvent extraction and wicking. Ceram. Int. 1996, 22, 7-14. [CrossRef]

28. Hwang, K.S.; Tsou, T.H. Thermal debinding of powder injection molded parts: Observations and mechanisms. Metall. Trans. A 1992, 23, 2775-2782. [CrossRef]

29. Xianfeng, Y.; Hehan, X.; Qinglong, H.; Zhe, Z.; Xiewen, X.; Li, Z.; Zhipeng, X. Study of thermal degradation mechanism of binders for ceramic injection molding by TGA-FTIR. Ceram. Int. 2019, 45, 10707-10717. [CrossRef]

30. Xie, H.; Jiang, J.; Yang, X.; He, Q.; Zhou, Z.; Xu, X.; Zhang, L. Theory and practice of rapid and safe thermal debinding in ceramic injection molding. Int. J. Appl. Ceram. Technol. 2020, 17, 1098-1107. [CrossRef]

31. You, W.K.; Choi, J.P.; Yoon, S.M.; Lee, J.S. Low temperature powder injection molding of iron micro-nano powder mixture. Powder Technol. 2012, 228, 199-205. [CrossRef]

32. Choi, J.P.; Lyu, H.G.; Lee, W.S.; Lee, J.S. Densification and microstructural development during sintering of powder injection molded Fe micro-nanopowder. Powder Technol. 2014, 253, 596-601. [CrossRef]

33. Leverkoehne, M.; Coronel-Hernandez, J.; Dirscherl, R.; Gorlov, I.; Janssen, R.; Claussen, N. Novel binder system based on paraffin-wax for low-pressure injection molding of metal-ceramic powder mixtures. Adv. Eng. Mater. 2001, 3, 995-998. [CrossRef]

34. Zaky, M.T.; Soliman, F.S.; Farag, A.S. Influence of paraffin wax characteristics on the formulation of wax-based binders and their debinding from green molded parts using two comparative techniques. J. Mater. Process. Technol. 2009, 209, 5981-5989. [CrossRef]

35. Hnatkova, E.; Hausnerova, B.; Filip, P. Evaluation of powder loading and flow properties of Al2O3 ceramic injection molding feedstocks treated with stearic acid. Ceram. Int. 2019, 45, 20084-20090. [CrossRef]

36. Hidalgo, J.; Jiménez-Morales, A.; Torralba, J.M. Torque rheology of zircon feedstocks for powder injection moulding. J. Eur. Ceram. Soc. 2012, 32, 4063-4072. [CrossRef]

37. ASTM International. Standard test method for transition temperatures and enthalpies of fusion and crystallization of polymers by differential scanning calorimetry. ASTM Int. 2012, D4318-08, 1-7.

38. Lamarre, S.G.; Demers, V.; Chatelain, J.F. Low-pressure powder injection molding using an innovative injection press concept. Int. J. Adv. Manuf. Technol. 2017, 91, 2595-2605. [CrossRef]

39. Metal Powder Industries Federation. Standard Test Methods for Metal Powders \& PM Products, Standard 42: Determination of Density of Compacted or Sintered Powder Metallurgy (PM) Products; Metal Powder Industries Federation: Princeton, NJ, USA, 1986.

40. Ferreira, T.; Rasband, W. The ImageJ 1.44 User Guide. Manager 2011, 27, 1-199.

41. Atre, S.V.; Enneti, R.K.; Park, S.J.; German, R.M. Master decomposition curve analysis of ethylene vinyl acetate pyrolysis: Influence of metal powders. Powder Metall. 2008, 51, 368-375. [CrossRef]

42. Demers, V.; Turenne, S.; Scalzo, O. Impact of binders on viscosity of low-pressure powder injection molded Inconel 718 superalloy. J. Mater. Sci. 2015, 50, 2893-2902. [CrossRef]

43. Thomas-Vielma, P.; Cervera, A.; Levenfeld, B.; Várez, A. Production of alumina parts by powder injection molding with a binder system based on high density polyethylene. J. Eur. Ceram. Soc. 2008, 28, 763-771. [CrossRef]

44. Samal, P.; Newkirk, J. Production of powder metallurgy carbon and low-alloy steels. Powder Metall. 2015, 7, 311-321. [CrossRef]

45. Wu, Y.; German, R.M.; Blaine, D.; Marx, B.; Schlaefer, C. Effects of residual carbon content on sintering shrinkage, microstructure and mechanical properties of injection molded 17-4 PH stainless steel. J. Mater. Sci. 2002, 37, 3573-3583. [CrossRef]

46. Da Silveira, W.; Wendhausen, P.A.P.; Klein, A.N. Study of the debinding rate on MIM parts using plasma assisted debinding. Mater. Sci. Forum. 2008, 591, 229-234. [CrossRef]

47. Medvedovski, E.; Peltsman, M. Low pressure injection moulding mass production technology of complex shape advanced ceramic components. Adv. Appl. Ceram. 2012, 111, 333-344. [CrossRef]

48. Zorzi, J.E.; Perottoni, C.A.; da Jornada, J.A.H. Hard-skin development during binder removal from Al2O3-based green ceramic bodies. J. Mater. Sci. 2002, 37, 1801-1807. [CrossRef]

49. Gorjan, L.; Dakskobler, A.; Kosmač, T. Strength evolution of injection-molded ceramic parts during wick-debinding. J. Am. Ceram. Soc. 2012, 95, 188-193. [CrossRef] 